\title{
0 Comparative Agendas Project na América Latina: dados e
} codificação

\section{Shaun Bevan ${ }^{1}$}

Anna M. Palau ${ }^{2}$

1 University of Edinburgh, Edinburgh - Reino Unido

2 University of Barcelona, Barcelona - Espanha

Esse artigo apresenta o sistema de codificação do Comparative Agendas Project, que é capaz de capturar a atenção política de maneira comparada e ao longo do tempo. Apresenta também uma ampla gama de dados coletados e em processamento na América Latina, já usando esse consolidado e confiável sistema de codificação. Embora não seja um sistema inédito, essa é a primeira vez que está sendo introduzido na América Latina e em um tipo de sistema político diferente do que se observa nas democracias da América do Norte e da Europa. Para isso, oferecemos um panorama do Comparative Agendas Project e de seu livro de códigos (Master Codebook), usado para obter dados de atenção política de forma comparada entre os países e suas agendas, ao longo do tempo. Esses detalhes são discutidos em relação a América Latina em geral e ao contexto nacional do Brasil, Colômbia e Equador, países da região que contam com a primeira leva de dados processados com esse sistema de codificação.

Palavras-chave: CAP; análise comparativa; América Latina; codificação; livro de códigos; master codebook.

\section{Comparative Agendas Project en América Latina: datos y codificación}

Este artículo presenta el sistema de codificación del Comparative Agendas Project, que es capaz de capturar la atención política de manera comparada y a lo largo del tiempo. Presenta también una amplia gama de datos recogidos y procesados en América Latina, sobre la base de este consolidado y fiable sistema de codificación. Aunque no sea un sistema inédito, esta es la primera vez que se introduce en América Latina y en un tipo de sistema político diferente del que se observa en las democracias de América do Norte y Europa. Para ello, ofrecemos una descripción del Comparative Agendas Project y de su libro de códigos (Master Codebook), usado para obtener datos de atención política de forma comparada entre países y distintos tipos de agendas a lo largo del tiempo. Esos detalles se discuten en relación con América Latina en general y con el contexto nacional de Brasil, Colombia y Ecuador, países de la región que cuentan con el primer conjunto de datos recogidos con ese sistema de codificación.

Palabras clave: CAP; análisis comparativo; América Latina; codificación; libro de códigos; master codebook.

\section{The comparative agendas project in Latin America: data and coding}

This paper introduces the Comparative Agendas Project system of coding as well as a wealth of gathered and in process data from Latin America using this established and reliable system for capturing policy attention comparatively and over time. While this is not the first introduction of the coding system, it is the first introduction aimed at Latin America and a new type of political system beyond North American and European democracies. First, we present an overview of the Comparative Agendas Project (CAP) and the Master Codebook used to create comparative policy attention data across countries, over time, and between agendas. These details of CAP are discussed for Latin America in general and for Brazil, Colombia and Ecuador, countries that recently started to gather data using these coding.

Keywords: CAP; comparative analyses; Latin America; coding; master codebook. 


\section{AGRADECIMENTO}

Este trabalho foi apoiado pelo projeto de investigação 'La oposición política en España: estrategias en la arena parlamentaria' (RTI2018-096950-A-I00).

\section{INTRODUÇÃO}

A codificação dos tópicos que orientam políticas públicas, como educação, segurança e habitação, pode ser feita de diversas maneiras, a partir de visões de mundo distintas e peculiares. O agrupamento de dados com base em padrões é usado tanto em técnicas de codificação por computador como humanas. Apesar dos contínuos avanços nos métodos computacionais, eles não são particularmente precisos quando são examinadas longas séries temporais ou em análises comparativas. Já a codificação humana também apresenta seus problemas. Pode-se perceber que a maioria das áreas de política pública como cultura, pesca e até contraterrorismo, do ponto de vista da política em si e dos legisladores, costumam apresentar-se de forma muito diferente dependendo do contexto. O Comparative Agendas Project (CAP) (ver https://www.comparativeagendas.net/), é uma comunidade de pesquisadores que atua nessas questões, trabalhando para enfrentar as dificuldades de classificação de políticas ao longo do tempo e entre os países.

Este artigo apresenta três dos mais novos projetos do CAP na América Latina: Brasil, Colômbia e Equador. Os países nessa região apresentam uma diversidade incrível, especialmente cultural. Mas ao mesmo tempo, apresentam aspectos em comum e problemas similares ainda não resolvidos, como corrupção, turbulência política e instabilidade das instituições. A capacidade de medir com precisão o processo político e as prioridades de seus atores por meio dos dados do CAP, permitirá que se explore a dinâmica da formação da agenda nos países latino-americanos numa perspectiva totalmente nova, abordando questões que até agora foram submetidas a pouca investigação empírica. Isso não apenas abrirá uma nova agenda de pesquisa na região, mas também proporcionará, de maneira mais ampla, oportunidades para estudos comparados. O presente artigo cobre o contexto político nesses países e alguns elementos que lhes são peculiares, bem como aborda algumas das pesquisas que podem ser realizadas em cada um e entre eles comparativamente, usando esse novo e aberto conjunto de dados.

As próximas sessões desse artigo apresentam, primeiramente, um histórico sobre o CAP e a ênfase do projeto na codificação das políticas públicas e não em seus objetivos. Na seção seguinte, explicamos como e por que o livro código do projeto foi criado. A seguir, tratamos das características dos dados recentes gerados pelos projetos no Brasil, Colômbia e Equador, explicando as particularidades dos países e sugerindo possíveis agendas de pesquisa. Por fim, concluímos com algumas reflexões gerais sobre o CAP, sua aplicação na América Latina e o potencial da pesquisa comparativa envolvendo outros países de fora da região.

\section{UMA POLÍTICA PARA A CODIFICAÇÃO COMPARADA}

As raízes do CAP derivam do US Policy Agendas Project (US PAP) (Projeto de Agendas de Políticas Públicas). É uma iniciativa já consolidada criada por Frank Baumgartner e Bryan Jones, utilizada amplamente tanto por profissionais quanto por acadêmicos e focada na elaboração de conjuntos de dados a partir de um sistema de codificação comum, abordando o conteúdo de políticas públicas de agendas políticas. O projeto iniciou suas atividades de codificação a partir das Audiências do Congresso dos 
EUA. Usando uma série de macro e subcódigos, o trabalho do US PAP resultou em um livro de códigos detalhado e abrangente (chamado Master Codebook), dando conta de todas as políticas do Governo Federal dos Estados Unidos (Jones \& Baumgartner, 2005). O Quadro 1 apresenta a nomenclatura dos macrocódigos de acordo com esse primeiro livro. O site da CAP mantém um livro de códigos completo e atualizado, incluindo subcódigos e anotações gerais (www.comparativeagendas.net).

\section{QUADRO 1 MASTER CODEBOOK DO CAP - MACROCÓDIGOS E SEUS TÓPICOS}

\begin{tabular}{|c|c|}
\hline Macrocódigo & Tópico \\
\hline 1 & Questões Macroeconômicas Nacionais \\
\hline 2 & Direitos e Liberdades Civis e das Minorias \\
\hline 3 & Saúde \\
\hline 4 & Agricultura \\
\hline 5 & Trabalho e Emprego \\
\hline 6 & Educação \\
\hline 7 & Meio-ambiente \\
\hline 8 & Energia \\
\hline 9 & Migrações e Refugiados \\
\hline 10 & Transporte \\
\hline 12 & Legislação, Crime e Família \\
\hline 13 & Políticas Sociais \\
\hline 14 & Habitação e Desenvolvimento Comunitário \\
\hline 15 & Comércio Interno e Setores Bancário e Financeiro \\
\hline 16 & Defesa \\
\hline 17 & Espaço, Ciência, Tecnologia e Comunicação \\
\hline 18 & Comércio Exterior \\
\hline 19 & Política Externa e Cooperação Internacional \\
\hline 20 & Governo e Administração Pública \\
\hline 21 & Terras Públicas, Gerenciamento de Águas e Território \\
\hline 23 & Política Cultural \\
\hline
\end{tabular}

Fonte: Elaborado pelos autores. 
Com o tempo e mesmo antes da criação do CAP, o livro de códigos do US PAP foi revisado, com ajustes como a decisão de tratar o tópico de questões familiares no macrocódigo que contempla os temas de lei e ordem ${ }^{1}$. O livro de código tem sido ajustado para acomodar novos tipos de dados, como por exemplo as informações da mídia, baseadas em mostras aleatórias de artigos de jornais. Essas fontes continham artigos sobre o placar de eventos esportivos, notas de falecimento e outros itens que não envolvem política. Nesse caso, novos códigos não relacionados à política foram criados para representar com precisão todos os dados de amostra.

Todos esses ajustes nos códigos, a exemplo das revisões que deram origem ao livro de códigos do CAP, seguem o que Bryan Jones chama de "primeira diretiva" do projeto. Segundo essa diretiva, os macrocódigos existentes não poderão ser combinados, mas outros podem ser criados para corresponder a interesses genuinamente novos ou para acomodar a eventual separação de códigos existentes. Por exemplo, relatórios meteorológicos exigiram um código relacionado a mídia dos EUA que fosse novo e não focado em políticas públicas. Um exemplo de fora dos Estados Unidos é o subcódigo migração, que tem sido destacado nos projetos do CAP na Europa já que o tema é relevante no contexto da União Europeia (Guiraudon, 2000).

\subsection{Definição dos dados do CAP}

A comunidade do CAP atualmente está com projetos na Alemanha, Austrália, Bélgica, Canadá, China, Coréia do Sul, Croácia, Dinamarca, Espanha, Estados Unidos (incluindo projetos específicos para os Estados da Flórida e da Pensilvânia), França, Hungria, Israel, Itália, Nova Zelândia, Países Baixos, Portugal, Reino Unido, Rússia, Suíça, e Turquia, bem como um projeto no âmbito da União Europeia e uma iniciativa na América Latina, com uma primeira leva de projetos no Brasil, na Colômbia e no Equador. Os dados do CAP incluem uma ampla gama de bases que usam o livro de códigos, ou o tem como referência para identificar, de forma consistente e sistemática, a atenção política dada às políticas públicas. Esse espaço que as políticas ganham na agenda pública é revelado a partir da análise de conteúdo de palavras faladas ou escritas. A atenção política é o foco substantivo de cada item no banco de dados. As observações podem variar e variam, desde questões legislativas e projetos de lei, até medidas mais agregadas, como questões do tipo "qual o problema mais importante", destinadas a captar as prioridades políticas do público (Bevan \& Jennings, 2014). Todos os dados seguem um conjunto comum de regras para codificar com precisão o foco da política em cada observação. A maioria dos conjuntos de dados do CAP armazena informações de longa data e inclui todas as observações dentro desse período. Cada conjunto de dados traz o máximo de informações possível sobre o item a ser codificado e informações de identificação, como títulos ou links para acesso aos documentos completos. Embora, na prática, direitos autorais ou outras questões legais possam limitar o quão abertos os dados podem ser, o ideal almejado é que sejam de total transparência e de completo acesso.

\footnotetext{
${ }^{1}$ A decisão de fundir códigos é a razão pela qual não há um macrocódigo 11 no livro de códigos do CAP. Originalmente designado ao tópico de questões familiares, o macrocódigo 11 foi englobado por outro relacionado a lei e ordem, considerando que o governo trata aspectos familiares (a exemplo do casamento ou custódia dos filhos) como questões jurídicas.
} 


\subsection{Codificação específica e limitada}

A codificação do CAP é específica e limitada a conteúdo relacionado a política. Embora o objetivo dos dados do CAP seja a codificação abrangente de grandes conjuntos de dados ao longo do tempo, seu foco está na atenção política. Os pesquisadores atuando na comunidade do CAP possuem formação em uma ampla diversidade de campos e subcampos, da Ciência Política ao Direito e a Mídia, ou em várias áreas da Sociologia. O ponto que une esses acadêmicos é o interesse pela atenção política. Esse foco mais geral - ao invés de uma ênfase nos partidos políticos, ou em como a mídia se envolve com a política, ou mesmo nas preocupações da sociedade em torno de determinadas questões - levaram a necessidade de um sistema de codificação robusto, mas limitado. A atenção, entretanto, é a condição elementar do processo de formulação de políticas que pode levar as políticas públicas a moverem-se numa direção específica, com base na maneira como se vê e/ou se expressa o problema público (policy framing) e nas preferências partidárias (ou outras preferências específicas). Focando apenas na atenção, os dados codificados do CAP podem não se adequar a muitas das questões políticas. No entanto, suas diretrizes claras e consistentes, bem como sua transparência (com a maioria dos dados na forma de texto bruto ou de informações usadas para codificar cada observação), faz com que adicionar 'preferência' ou outros conceitos a esses dados seja algo geralmente bastante simples e a ser fortemente encorajado. Embora nem todos os conjuntos de dados possam oferecer dados brutos por motivos práticos ou legais, quando eles estão disponíveis, os usuários podem usar facilmente os recursos do CAP para capturar a atenção, ou como uma base de dados para políticas públicas usando qualquer outro modelo de codificação adicional que desejarem.

\subsection{Codificar a política pública e não o seu objeto}

Uma política não é igual ao seu objeto. Por exemplo, a crise financeira global foi objeto de muitas políticas diferentes em todo o mundo. Essas políticas enfocavam, entre outros, o emprego, a regulamentação dos setores financeiros e a confiança do consumidor. Na verdade, em muitos países, a austeridade significava que praticamente todas as áreas políticas eram afetadas pelo orçamento. As soluções para a crise, certas ou erradas, não passavam somente pela crise em si, mas em como todas as políticas poderiam ou deveriam funcionar durante um período de angústia econômica. As soluções para esse objeto - o problema da crise financeira - incluíram cortes de gastos, reforma tributária, mudanças na previdência social e apoio a novos empregos e negócios. A crise foi um choque que levou a mudanças na maioria das áreas de política pública e ela continua a ter efeitos até os dias atuais.

Essa escolha de se concentrar na substância da política é uma das críticas mais comuns feitas ao CAP (Dowding, Hindmoor, \& Martin, 2016). Essa crítica, no entanto, está relacionada a sua abordagem ou foco e não a qualidade do projeto. Obviamente, para compreender totalmente a resposta do governo a um grande problema, a codificação do CAP por si só não é suficiente. Pegando um outro objeto para elaboração de política pública, como o terrorismo, por exemplo, vê-se que é um problema que pode ser enfrentado por diferentes atores, como a polícia, os militares ou instituições mais globais. A ameaça do terrorismo também pode ser combatida por diferentes meios, como vigilância, medidas de segurança adicionais nos portos de entrada, ou monitoramento de atividades financeiras suspeitas. Tal como acontece com a crise financeira, o alvo do terrorismo pode e é abordado através de muitas áreas políticas. 
Para pesquisadores interessados em políticas destinadas a determinados objetos, é necessária uma codificação adicional relacionada a esses objetos. Isso pode ser feito buscando ou adicionando novos conjuntos de códigos aos dados brutos do CAP, o que certamente é um foco digno de pesquisa. No entanto, identificar quais os objetos da política é algo bem menos previsível, já que se alteram ao longo do tempo e podem ser mais exclusivos para cada país.

\section{0 MASTER CODEBOOK DO CAP}

A elaboração de um livro de código que abrange todas as políticas governamentais realizadas nos últimos 100 anos, da América do Norte à Europa Oriental e, cada vez mais, de países democráticos a não democráticos, é a realização mais significativa do livro de código (Master Codebook) do CAP. No entanto, também trata-se de um acordo, uma seleção de 21 macrocódigos e mais de 200 subcódigos que deixam de lado detalhes de grandes eventos, como por exemplo a reunificação alemã, sistemas políticos incomuns como monarquias constitucionais e disputas por territórios. No entanto, os projetos individuais ligados ao CAP são livres para criar livros de código específicos, capazes de abordar essas e outras áreas e contextos políticos exclusivos, desde que o acordo em torno dos códigos do Master Codebook não seja violado.

Dito isso, nem sempre se consegue harmonizar os dados de forma clara, até porque, todos os anos, um ou vários novos projetos aderem ao CAP. Até a criação do Master Codebook em 2014, os vários projetos ligados ao CAP trouxeram para o livro de códigos algumas alterações bem particulares, oriundas de reinterpretações de menor relevância de códigos que já existiam e que não levaram em conta o objetivo de favorecer análises comparadas. A falta de uma liderança hierárquica forte e/ou de uma fonte central de financiamento têm representado um ponto chave para a riqueza da amplitude de cobertura obtida com os dados do CAP, o que, talvez surpreendentemente, tem funcionado bem. Mas a coordenação é fundamental e a codificação precisava de um nível de coordenação e controle que não se encaixava nesse arranjo de liderança difusa. Como resultado, ocorreram muitos desvios de significados, cobertura e aplicação dos códigos, o que resultou em um problema sério, especialmente no nível dos subcódigos. Enquanto a maioria dessas alterações particulares feitas pelos projetos fazia sentido ao lidar com seus contextos singulares, elas também levaram a mal-entendidos ou a produção de muitas soluções diferentes para problemas compartilhados. Algumas políticas acabaram sendo consideradas totalmente exclusivas, mesmo quando conceitualmente se encaixavam em códigos já existentes - ao menos para fins de comparação. Internamente, cada projeto faz um excelente trabalho de codificação e reconciliação com os macrocódigos, chegando em acordo em aproximadamente $90 \%$ dos casos, tendendo a aumentar depois de uma 'limpeza' adicional que eleva ainda mais a qualidade dos dados finais. É fácil esquecer que o processo de acordo também precisa ser abordado em todos os projetos.

Em geral, resultados comparáveis eram observados antes mesmo da criação do Master Codebook, em virtude das questões que concentram a atenção do governo (Jennings et al., 2011) e de uma lei geral dos orçamentos públicos observada empiricamente (Jones et al., 2009). No entanto, as análises comparativas foram impossibilitadas dado o grande número de incompatibilidades entre os livros código elaborados em cada país. Algumas delas eram óbvias, como a maneira pela qual a migração era tratada: às vezes como política exclusiva do país, ou como política ligada a direitos 
civis, ou como uma política relacionada com a força de trabalho; ou seja, era uma política alvo de 'recodificação localizada'. Outras diferenças não pareceram graves o suficiente para minar o trabalho conjunto, sendo possível acomodar os macrocódigos e os países de forma a conseguir uma análise comparativa sem afetar substantivamente os resultados (Jennings et al., 2011). Antes da conclusão do Master Codebook, os pesquisadores tinham que lidar com mais de 450 subcódigos (ao invés dos 225 originalmente elaborados), pelo menos parcialmente exclusivos, em mais de uma dúzia de projetos. Embora a maioria deles tenha sido criado como uma adição feita em virtude de diferenciações menores, era difícil dizer como os subcódigos deveriam ser combinados sem uma ferramenta que pudesse servir de orientação.

O início do processo de elaboração do Master Codebook do CAP envolveu um grande número de pessoas da comunidade do projeto, a partir da base elaborada por Jeroen Joly e Herschel F. Thomas III, que fizeram um trabalho amplo de comparação entre diversos livros de códigos. No entanto, a discussão sobre como a codificação foi concluída na prática ainda era limitada. Essa etapa inicial foi usada em alguns estudos comparativos iniciais do CAP (Baumgartner, Brouard, Green-Pedersen, Jones, \& Walgrave, 2011), que tiveram os macrocódigos como foco predominante. Ainda havia, portanto, muito trabalho a ser feito no nível dos subcódigos e como seriam aplicados na prática, deixando questões persistentes em aberto. A história e a lógica por trás da criação do livro de códigos inicial do CAP são apresentadas em detalhes na presente seção, para que os pesquisadores possam ter mais claro as limitações desse instrumento e também para que o CAP possa reafirmar que tem de fato um sistema de codificação consistente que permite seu uso entre os países, ao longo do tempo e abordando as diversas áreas de políticas públicas.

\subsection{A elaboração do livro de códigos - Master Codebook}

O processo de criação do livro de códigos começou cedo, com discussões regulares nas conferências do CAP, que passaram a ser anuais desde que os primeiros projetos de países europeus receberam financiamento. Esse trabalho começou de fato no verão de 2012, liderado por Shaun Bevan com o apoio dos investigadores principais dos projetos. Para iniciar o processo, um conjunto de objetivos simples e claros foi estabelecido em um memorando explicativo detalhando o processo, que foi então posto em discussão. Os objetivos eram os seguintes: (1) Criar um Master Codebook que permitisse comparações precisas em todos os conjuntos de dados do CAP; (2) Minimizar a quantidade geral de trabalho, buscando um meio-termo comum entre os projetos, em vez de pedir que eles usassem um livro código de um país qualquer; e (3) Sempre que possível, realizar agrupamento em códigos existentes, evitando a necessidade de recodificação.

O primeiro objetivo foi essencial para manter o CAP amplo e inclusivo em todos os contextos comparativos captados pelos projetos. O segundo objetivo foi consolidar o Master Codebook ao evitar impor que todos aplicassem um livro de códigos de um projeto já existente. Além de conquistar a boa vontade geral, essa foi uma decisão prática, pois o meio-termo, ou os elementos comuns dos livros de código de cada projeto representaram também o melhor ponto de comparação. O terceiro e último objetivo era o mais prático, pois muitos projetos careciam de recursos adicionais ou nunca haviam recebido financiamento para o volume de trabalho que cada um, individualmente, precisava executar para obter resultados realistas. O objetivo era também comparar o trabalho existente ao invés 
de criar novos códigos ou mais trabalho. No geral, os objetivos levaram a um livro de códigos que serviu como um mínimo denominador comum capaz de manter um alto nível de detalhe enquanto dividia o trabalho entre os projetos para criar uma codificação para a atenção política que pudesse servir tanto a projetos existentes como a iniciativas futuras.

Para iniciar o trabalho, cada projeto foi convidado a criar um livro de código em inglês para facilitar as reuniões presenciais entre os investigadores principais dos projetos, codificadores, coordenadores, e Shaun Bevan. Os livros criados para as reuniões presenciais foram comparados com os outros já existentes, gerando um rascunho do Master Codebook para identificar possíveis diferenças em como os códigos estavam sendo aplicados. As equipes fizeram um exercício de codificação em comum, usando como base os Atos do Parlamento do Reino Unido com um grande número de casos difíceis ou limítrofes. A intenção do exercício foi destacar como cada projeto abordou as áreas com mais chance de serem consideradas 'problemáticas'. Reuniões foram realizadas para discutir os exercícios de codificação, a comparação entre os livros de código em língua inglesa e o rascunho do Master Codebook, bem como quaisquer outras questões ou preocupações que as equipes tivessem. Essas reuniões normalmente duravam entre um e um dia e meio, sendo que alguns problemas eram resolvidos de imediato, enquanto outros eram discutidos em reuniões seguintes com outros projetos, e alguns ainda foram resolvidos posteriormente ao longo do processo. Após essa reunião, o Dr. Bevan criou um Master Codebook revisado, com 21 macrocódigos e 213 subcódigos.

Com o Master Codebook recém elaborado e um grande número de pequenas, mas importantes inconsistências abordadas nas reuniões presenciais, outro memorando foi enviado às equipes, explicando as principais diferenças entre o Master Codebook e os outros livros de códigos em trabalho até então. Uma discussão foi realizada na conferência do CAP de 2013 na Bélgica, onde as revisões foram explicadas e questionadas em detalhes. Com base nesse debate e na revisão do livro de códigos, o Dr. Bevan propôs algumas pontes entre os projetos existentes e o livro, enviando esse conteúdo às equipes para comentários adicionais. Fazendo as alterações eventualmente necessárias, as equipes usaram essas 'pontes' para retrabalhar seus dados e se encaixar no Master Codebook. Embora o número de macro e subcódigos se manteve inalterado ao longo desse processo, foram feitas revisões significativas nos nomes de cada código para que ficassem o mais geral e comparável possível.

\subsection{Detalhes... os detalhes são tudo!}

A descrição feita acima mostrou que o processo de criação do Master Codebook foi intenso, bastante direto e longe de ser fácil. O esforço de criar algo verdadeiramente comparável entre os projetos envolveu uma quantidade enorme de detalhes, em parte, contextuais. A pesca, por exemplo, é um dos pilares da agricultura ou aquicultura em muitas nações marítimas como a Dinamarca. Entretanto, foi um item refletido tardiamente em países tão vastos como os Estados Unidos, e praticamente um 'não-problema' em nações sem litoral, como a Suíça. Ou seja, tem-se um problema particular e fundamental em determinado contexto, que é ao mesmo tempo pouco relevante ou nem pensado em outros; levando a conclusão que a abrangência das políticas é encarada diferentemente de acordo com características locais dos países e também ao longo do tempo. Foi esse o desafio que levou os projetos a elaborarem mais de 450 subcódigos (o dobro dos códigos elaborados no US PAP) antes 
da criação do Master Codebook. A maioria deles não passava de revisões com o objetivo de capturar pequenas, mas importantes diferenças dentro dos projetos. No entanto, alguns subcódigos eram mais exclusivos, como o papel da religião no governo em algumas nações, ou divisões feitas em códigos relacionados a direitos civis para captar nuances adicionais. Assim como a pesca, a cultura não tinha nenhum análogo real no livro de código original dos EUA e serviu como um item de constantes debates entre os projetos.

À medida que o número de projetos cresceu, duas dessas revisões surgiram claramente como principais áreas de política pública. A primeira, migração, sempre foi pelo menos um subcódigo, com muitos países se concentrando no tema sob o ponto de vista dos direitos civis ou das questões trabalhistas. O grande número de projetos da UE no CAP reconheceu a migração como uma questão primordial, que teve um papel significativo na criação da UE (Guiraudon, 2000) e continua a afetar a política contemporânea.

A segunda revisão, que trouxe a questão da preservação e promoção da cultura e a continuidade de línguas nativas, mostrou uma grande variação. As preocupações com as influências culturais externas de filmes e TV, bem como a prevalência do inglês em diferentes formas, levaram nações como a Itália e a França a produzir um grande arcabouço de políticas culturais. Muitas nações não apenas promovem sua própria cultura por meio de financiamento, mas também optam por dublar filmes e programas de TV produzidos originalmente em outros idiomas. Embora os EUA e o Reino Unido, que têm papéis importantes a desempenhar na produção de mídia global, produzam muito pouca ou nenhuma política cultural, dependendo da perspectiva de análise, essa política é claramente importante e deve ser comparada. O fato de os EUA terem tão pouca política cultural acrescenta muito à validade externa do projeto, dado que esse país tem pouca preocupação ou necessidade de proteger a cultura inglesa ou americana de influências externas. Tanto a cultura como a migração foram adicionadas ao Master Codebook como macrocódigos, refletindo o fato de serem áreas políticas primordiais para a maioria dos projetos do CAP.

O Master Codebook aborda questões comparáveis menores e numerosas, garantindo que cada projeto capture e codifique políticas públicas da mesma maneira. Isso é feito por meio de pontes entre os livros de código de cada projeto e o Master Codebook. O uso de uma forma comum e bem estabelecida de codificação permite que o CAP seja adotado na análise interna de uma iniciativa e na comparação entre projetos diferentes, ao longo do tempo e entre os conjuntos de dados de cada país. A seguir apresentamos as bases de dados desenvolvidas na América Latina até o momento pelas novas iniciativas envolvidas no CAP.

\subsubsection{Base de dados latino-americanas}

O Comparative Agendas Project tem sido desenvolvido em três países da América Latina: Brasil, Colômbia e Equador. Até o momento, esses países criaram os bancos de dados resumidos no Quadro 2. O principal objetivo desses dados é reunir informações que permitam explorar o impacto de fatores institucionais, preferências de política e eventos externos nas dinâmicas da agenda desses três países. Para isso, os três coletaram e codificaram dados sobre os discursos presidenciais, a agenda legislativa e a agenda da mídia. A seguir explicamos as principais características e o conteúdo dessas bases de dados e fornecemos informações sobre as equipes de pesquisa responsáveis por sua coleta e codificação. 


\section{QUADRO 2 PRINCIPAIS BASES DE DADOS CODIFICADAS NO BRASIL, NA COLÔMBIA E NO EQUADOR USANDO A METODOLOGIA DO CAP}

\begin{tabular}{|c|c|c|}
\hline & Conjunto de dados & Período \\
\hline \multirow[t]{8}{*}{ Brasil } & $\begin{array}{l}\text { Opinião Pública (série de pesquisas de opinião: Qual o } \\
\text { Problema Mais Importante do País?) }\end{array}$ & $1996-2018$ \\
\hline & Emendas Constitucionais & $1992-2017$ \\
\hline & Decretos Legislativos & \\
\hline & Leis e Leis Complementares & \\
\hline & Medidas Provisórias & $\angle 000-\angle 014$ \\
\hline & Decreto Presidencial & \\
\hline & Mensagens ao Congresso Nacional & \\
\hline & Discursos de Posse & 2003-2016 \\
\hline \multirow[t]{5}{*}{ Colômbia } & Projeto de Lei & \\
\hline & Proposta de Emenda Constitucional & 1994-2018 \\
\hline & CONPES & \\
\hline & Mídia (Revista Semana) (em andamento) & \\
\hline & Legislação & $1992-2019$ \\
\hline \multirow[t]{3}{*}{ Equador } & Discursos Presidenciais & 2007-2019 \\
\hline & Leis Orgânicas & $2009-2019$ \\
\hline & Media (El telégrafo e El Comercio) & $2014-2019$ \\
\hline
\end{tabular}

Fonte: Elaborado pelos autores.

A concentração de poder no executivo, e especificamente na presidência, é um elemento característico em países latino-americanos, formando um "hiperpresidencialismo" que os diferencia em muito de outros países como os Estados Unidos ou outros europeus que adotam esse sistema de governo. Nos três países, o presidente é escolhido por eleição popular, por maioria absoluta (em dois turnos caso no primeiro nenhum dos candidatos obtiver tal maioria). O poder do presidente é mais restrito na Colômbia, onde a presidência é limitada a um único mandato, enquanto que no Equador e no Brasil o presidente pode ser reeleito a dois mandatos consecutivos. No caso do Equador essa faculdade foi obtida após uma polêmica reforma constitucional. Em 2015, Correa forçou a legislativo a aprovar uma medida que permitia reeleições presidenciais ilimitadas; entretanto, em 4 de fevereiro de 2018, em um referendo nacional convocado por Moreno, os equatorianos votaram de forma esmagadora para limitar o tempo máximo na presidência em dois mandatos (Tartakoff, 2019, p. 15). Para analisar a agenda do executivo, os três países criaram bancos de dados com os discursos presidenciais. O Brasil coletou informações de discursos dos períodos 2003-2016, abrangendo as falas de Lula da Silva (2003-2011) e Dilma Rousseff (2011-2016). Os dados são baseados nas Mensagens ao Congresso Nacional, onde o presidente expressa as prioridades políticas para o próximo ano. 
A equipe equatoriana coletou informações sobre os discursos presidenciais do período 2007-2019, que incluem as presidências de Rafael Correa e Lenín Moreno, enquanto a Colômbia, até agosto de 2019, ainda não havia codificado os discursos do executivo.

Os três países também coletaram informações sobre a agenda substantiva do executivo e do parlamento. Colômbia e Brasil apresentam legislativos bicamerais, enquanto no Equador esse poder é unicameral e eleito por meio de representação proporcional. Na América Latina, os legislativos são inerentemente fracos, atuando de maneira subserviente em relação ao presidente, participando de um mesmo sistema integrado e orgânico (Kline, Wade, \& Wiarda, 2018). Os legislativos muitas vezes não têm o direito de propor ou vetar leis (o Congresso do Equador pode) mas acabam funcionando mais como instituições que aconselham e aprovam atos presidenciais. No Brasil o Congresso Nacional tem comparativamente mais poder e independência do que no Equador e na Colômbia. Isso permitiu, por exemplo, que o Congresso removesse Dilma Rousseff da presidência em 2016 em meio a denúncias de corrupção. Até o momento, o Brasil coletou informações sobre Emendas Constitucionais no período 1992-2017, e sobre Leis, Leis Complementares, Decretos Legislativos, Medidas Provisórias, Decretos Presidenciais e Mensagens ao Congresso Nacional no período 2003-2014. No caso da Colômbia, a constituição de 1991 concedeu mais poderes ao Congresso, mas o executivo ainda predomina. A equipe do CAP codificou leis estabelecidas no período de 1992-2018, e projetos de lei para modificar a Constituição, lançados no período de 1994-2018. Os documentos do CONPES, que se referem a relatórios de políticas públicas elaborados pelo Conselho Nacional de Política Econômica e Social, a mais alta autoridade nacional de planejamento colombiana (sob a direção do Presidente), foram codificados para o período 1994-2018. No Equador, foram codificadas todas as Leis Orgânicas aprovadas durante as presidências de Correa e de Moreno.

Finalmente, a equipe do Brasil também codificou a opinião pública (usando a série de pesquisas de opinião: Qual o Problema Mais Importante do País?) para o período 1996-2018, enquanto que na Colômbia e no Equador foram desenvolvidos bancos de dados abrangentes e de longa data com as histórias cobertas nas primeiras páginas dos jornais. No Equador, a mídia foi alvo da pouca tolerância do presidente Correa aos seus críticos (Collins, 2008, p. 308), sendo que usou agressivamente os tribunais contra a mídia para intimidá-los. Correa processou o El Universo, um dos principais jornais do país depois que um jornalista escreveu um artigo acusando-o de responsabilidade pelas mortes de civis em uma rebelião policial em 2010. Embora no final o presidente tenha perdoado o acusado, o tribunal decidiu a seu favor, sentenciando o jornalista a três anos de prisão e a uma multa no valor de $\$ 40$ milhões de dólares. A equipe equatoriana codificou as primeiras páginas do El Telégrafo e El Comercio para o período 2014-2019. A Colômbia começou a codificar a Revista Semana (uma revista política semanal) para o período 1994-2018 (trabalho em andamento).

\subsection{Equipes de pesquisa na América Latina}

No Brasil, os dados foram coletados originalmente por Ana Cláudia Niedhardt Capella e Felipe Gonçalves Brasil com a colaboração de alunos de graduação da Universidade Estadual Paulista (UNESP) e alunos de pós-graduação da Universidade Federal de São Carlos (UFSCar). As instituições patrocinadoras são Departamento de Administração Pública da Universidade Estadual Paulista (UNESP), Programa de Pós-Graduação em Ciência Política da Universidade Federal de São Carlos (UFSCar). O financiamento veio do Conselho Nacional de Desenvolvimento Científico e Tecnológico 
(CNPq) e da Fundação de Amparo à Pesquisa do Estado de São Paulo (FAPESP) ${ }^{2}$. No Equador, Pablo Ruiz Aguirre, da Universidade Internacional do Equador (UIDE) - Loja, é o responsável pelo projeto e codificou a maior parte dos dados também com o apoio de alunos de graduação. O suporte financeiro foi oferecido pela Universidade de Loja. Juan Guillermo Vieira Silva, da Universidad Nacional de Colombia, lidera e codifica os dados colombianos.

\section{ESPECIFICIDADES DOS PAÍSES LATINO-AMERICANOS}

Todos os países latino-americanos vivenciaram nas últimas décadas um processo importante de modernização, democratização e integração à economia global (Kline et al., 2018). No entanto, a região ainda é caracterizada por uma grande diversidade linguística, étnica, geográfica, econômica e política, e as formas como se apresentam a democracia e os sistemas econômicos e políticos, são muito diferentes do que se observa nos Estados Unidos e na Europa, o que torna a análise desses países particularmente interessante do ponto de vista do estabelecimento de agendas. A seguir, as principais especificidades e particularidades de cada país serão examinadas em relação ao período coberto pelos conjuntos de dados gerados, com o objetivo de oferecer uma lista não exaustiva do que pode ser feito com os dados. Entre as principais contribuições da comunidade do CAP está a criação de informações empíricas que possam permitir aos pesquisadores avaliar as tendências nas dinâmicas da agenda $\mathrm{e}$ ajudar a responder a uma série de perguntas. O que pretendemos aqui é enfatizar eventos políticos relevantes, tais como mudanças de presidências, problemas estruturais (por exemplo, corrupção e violência) e processos de mobilização social (de movimentos indígenas a feministas) com capacidade de influenciar as agendas nestes países.

\subsection{Brasil}

O Brasil é um bom exemplo de como uma mudança na presidência pode transformar a agenda política dos países latino-americanos. O presidente Lula da Silva de 2003 a 2011 reduziu significativamente os níveis de pobreza ao implementar ambiciosos programas de bem-estar social e, ao mesmo tempo, melhorar a economia do país, reduzindo a inflação e contendo gastos fiscais. Sua agenda reformista se encaixa no movimento de desenvolvimento pós-neoliberal que no Brasil e em outros países como o Equador, prometeu aprofundar a democracia, redistribuir riqueza, combinar igualdade social e crescimento econômico em um "novo socialismo do século 21" (North \& Clarck, 2018). Ao contrário de outros líderes políticos da região, a exemplo de Correa no Equador, Lula e outros presidentes do Brasil resistiram à tentação de estender seu tempo no poder ampliando mandatos ou as possibilidades de reeleição. Após o impeachment de Rousseff, a presidência de Michel Temer, de 2016 a 2019, caracterizou-se por aumentar os níveis de pobreza e o descontentamento público com decisões políticas polêmicas e chocantes, como a remoção de todas as mulheres do governo. Mais recentemente, a chegada de Bolsonaro à presidência - um militar da reserva, conservador da extrema direita, e com fortes ligações com a igreja evangélica - certamente transformará as prioridades políticas no país. Os conjuntos de dados criados pela equipe de pesquisadores do Brasil permitirão

\footnotetext{
${ }^{2}$ Processo no 471414/2014-0 - chamada MCTI/CNPQ/MEC/CAPES No 22/2014; Processo no 424398/2018-4 - chamada MCTIC/CNPq No 28/2018; Processo n 2018/16289-3; Processo nº 2018/11032-4; Processo n 2016/21653-0.
} 
análises e comparações em relação a atenção política entre essas diferentes presidências e, ao mesmo tempo, ajudarão a abordar questões importantes de representação política, como até que ponto esses presidentes cumprem suas promessas ou respondem às prioridades públicas.

O Brasil sofre de problemas estruturais profundos e permanentes que também podem influenciar a dinâmica de formação da agenda. Um problema que há muito caracteriza o país, tendo profundas ligações com a instabilidade política e econômica, é o tema da corrupção. O Brasil se constitui num sistema político baseado no clientelismo, enraizado na corrupção sistêmica, apresentando uma situação de corrupção generalizada, em todos os níveis de governo, com raízes profundas e alimentadas sobremaneira tanto pela ineficiência jurídica como por um sistema político multipartidário que demanda a formação de coalizões para aprovar legislação. $O$ próprio Lula, o presidente mais popular da história do Brasil, acabou se envolvendo em escândalos de corrupção, tendo sucesso em movimentar sua agenda no Congresso porque estava pagando as pessoas para isso (Crandall, 2018, p. 129; Gonçalves \& Niedhardt, 2019). Sua sucessora, Dilma Rousseff, foi submetida a um processo de impeachment sendo acusada de "crimes de responsabilidade" devido ao suposto uso de subterfúgios fiscais conhecidos como "pedaladas", para cobrir os custos de gastos sociais (Fogel, 2019, p. 154). O impeachment de Rousseff, que foi substituída por Michel Temer, revelou a natureza autocentrada do Congresso, uma vez que ficou evidente que os parlamentares tentaram desviar a atenção das investigações a respeito de seus próprios casos de corrupção (Crandall, 2018).

A novidade no tema da corrupção é que o público ficou menos tolerante, um fenômeno que se deu em decorrência da consolidação de uma classe média que, junto com um grupo de promotores dispostos a aplicar a lei e a meios de comunicação mais agressivos, formou um conjunto que fortaleceu medidas anticorrupção. A corrupção tem demonstrado gerar grande impacto político no Brasil influenciando até mesmo o resultado das eleições de 2018, depois que o juiz Sérgio Moro condenou Lula a nove anos e meio de prisão, proibindo-o de concorrer às eleições de 2018 e deixando o campo aberto para o líder de extrema direita Bolsonaro assumir a presidência (Fogel, 2019). Nesse contexto, marcado pela ideia de que a corrupção não é um problema sistêmico no Brasil, mas sim gerado pelo Partido dos Trabalhadores, um governo mais próximo aos militares foi apresentado como menos corrupto, legitimando a ideia de que Bolsonaro poderia restaurar a credibilidade da política brasileira (Fogel, 2019). Assim, embora a população como um todo e as elites políticas devam concordar que a corrupção é uma questão que obrigatoriamente deve ser combatida (Adler \& Wilkerson, 2013) e erradicada, ainda sabe-se pouco sobre até que ponto as diferentes presidências e legislativos priorizaram essa questão na agenda política ao longo do tempo em comparação com outras questões também prementes.

Outro problema estrutural do país é a violência. Ao contrário de outras nações latino-americanas, mesmo tendo vivenciado golpes militares, o Brasil se caracteriza por ter evitado rupturas políticas e sociais radicais. O país viveu uma independência não violenta de Portugal, mas foi palco de golpes militares ao longo do século XX, sendo o mais importante deles em 1964, levando o país a 21 anos de regime militar. Os níveis de repressão durante esses anos, entretanto, não alcançaram os níveis de outros regimes militares latino-americanos ocorridos no mesmo período. Ainda assim, a violência é um problema social de grandes proporções. O Brasil está entre os países com o maior número de mortes violentas do mundo, sendo essa violência o resultado de uma combinação entre desigualdade de renda, pobreza, tráfico de drogas e falta de uma presença efetiva do Estado (Crandall, 2018). Organizações criminosas controlam as cidades brasileiras promovendo o tráfico de drogas, roubos, 
extorsões e outros crimes, especialmente nas favelas, onde a criação de milícias para lutar contra as gangues do narcotráfico aumentou a violência a níveis dramáticos. A implantação de "Unidades de Polícia Pacificadora" (UPPs), melhorou a relação entre a polícia e os moradores da favela, resultando na diminuição dos homicídios e roubos. A análise da atenção à violência a partir de uma perspectiva empírica de formação de agenda, permitirá a exploração de questões como, se esse é um tema que pertence ao foco de atenção de partidos de direita, como tem sido tradicionalmente o caso nos EUA e na Europa, ou, pelo contrário, o fato de ser um problema estruturalmente importante significa que foi priorizado por todos os atores políticos com pouca variação ao longo do tempo.

Por fim, a pressão para construir um belo Rio de Janeiro primeiro para a Copa do Mundo de 2014 e depois para as Olimpíadas de 2016, ilustra o impacto dos eventos externos nas dinâmicas da agenda, já que esses dois momentos trouxeram o problema das favelas, até então historicamente ignorado, à tona na agenda política, considerando-se sua erradicação forçada em algumas regiões. A necessidade de financiar estádios multimilionários e infraestruturas para esses eventos contribuiu com a contração econômica do país e o crescente descontentamento público em relação a gestão da presidente Dilma Rousseff. O país também dá espaço para que se explore o papel dos movimentos da sociedade civil como atores que definem a agenda. O Movimento dos Trabalhadores Rurais Sem Terra (MST) é considerado um dos movimentos sociais mais influentes da América Latina (McNee, 2005). Fundado em 1984, luta pela reforma agrária radical, ou seja, a intervenção do Estado para reverter tendências históricas de concentração fundiária e na promoção de uma sociedade mais justa. Lula foi acusado de ter sido irresponsável ao mostrar apoio público ao movimento, sendo que esse representou um dos elementos da sociedade civil que mais perturbou a presidência de Temer, afetando sua popularidade.

\subsection{Colômbia}

O caso colombiano provavelmente ilustra os efeitos que problemas profundos e estruturais na formação da agenda podem ter na agenda política em si. Ao contrário do Brasil, o uso da violência no contexto político é uma característica no país desde a independência. A Colômbia foi palco de oito guerras civis durante o século XIX e o uso da violência caracterizou a relação entre os partidos Liberal e Conservador, sendo que ambos foram fundados em 1840. A violência se consolidou como forma normal de lidar com a política também no século XX, no período conhecido como "La Violencia". Nesse período, os dois principais partidos entraram em uma guerra sangrenta que durou de 1946 a 1960, sendo que a partir dos anos 70 emergiram novas formas de violência no país (Kline, 2018). Grupos guerrilheiros marxistas seguidos de grupos de "autodefesa" ou "paramilitares" e posteriormente traficantes de drogas levaram o país a uma situação complexa. Nos anos 90, a Colômbia foi considerada um estado falido por causa do crime e da violência endêmica e do terrorismo de âmbito nacional que resultou no deslocamento da população rural e, devido ao sequestro generalizado, profissionais e pessoas das classes mais altas passaram a emigrar (Bruneau \& Goetze , 2019, p. 3). Por isso, a violência política e especialmente a atuação de grupos paramilitares e guerrilheiros ocupam posição de destaque na agenda política e midiática.

Todos os presidentes colombianos tentaram acabar com a violência, mas o presidente Álvaro Uribe, 2002-2010 foi o primeiro a levar as Forças Armadas Revolucionárias da Colômbia (FARC) a sentar à mesa de negociação, em um processo que continuou com o presidente Juan Manuel Santos, 2010-2018, 
que havia sido Ministro da Defesa do presidente Uribe de 2006-2010. Essa medida resultou em grande redução da violência no país. As negociações de paz conduzidas por Santos para assinar um tratado de depor as armas com as FARC começaram formalmente em 2012. Embora o povo colombiano tenha rejeitado o tratado quando 50,22 votaram contra ele em um plebiscito em outubro de 2016, o documento foi finalmente aprovado, após muitas mudanças feitas pelo Senado em novembro de 2016. Santos ganhou o Prêmio Nobel da Paz em 2016 pelo sucesso nas negociações com as FARC. O sucessor do presidente Santos, Iván Duque, eleito em 2018, enfrenta muitos desafios. O progresso na implementação do acordo de paz tem sido lento e o tráfico de drogas atingiu novos recordes em 2017, quando as plantações de coca foram estimadas em 209.000 hectares, com 921 toneladas métricas de produção de cocaína anualmente (em 1999, ano em que o Congresso dos EUA considerou haver uma emergência que justificou a elaboração do Plano Colômbia, havia 136.000 hectares de coca produzindo cerca de 500 toneladas métricas de cocaína) (Spencer, 2019, p. 83).

O efeito político da violência na Colômbia foi tão grande que grupos paramilitares, guerrilhas e organizações criminosas restringiram por décadas o papel dos movimentos da sociedade civil e grupos de direitos humanos. Isso explica, por exemplo, por que os grupos de mulheres não são tão organizados como em outros países latino-americanos. Somente grupos indígenas conseguiram realizar algumas de suas reivindicações políticas. Mesmo que a partir da década de 70 a população indígena tenha se mobilizado politicamente em quase todos os países latino-americanos, apenas na Colômbia essa população alcançou autonomia político-territorial quando a constituição de 1991 elevou as reservas indígenas ao status de governos municipais (Kline \& Wade, 2018). Atualmente, embora a violência e grupos criminosos ainda sejam um grande problema no país, a aprovação do tratado de paz proporcionou a oportunidade para novos grupos advogarem pela entrada de temas na agenda política, como direitos das mulheres, população LGBT ou combate a corrupção (Kline, 2018, p. 190). Pela primeira vez na Colômbia, as vozes de movimentos sindicais, camponeses, mulheres, grupos indígenas e ambientalistas encontram expressão superando velhas práticas corporativistas amplamente associadas à igreja, às forças armadas, às elites fundiárias e empresariais (North \& Clarck, 2018). Uma questão chave a ser analisada de maneira comparada é por que essa variedade de organizações da sociedade civil tem diferentes capacidades de mobilizar e influenciar a agenda política em diferentes países latino-americanos.

\subsection{Equador}

No Equador ocorreram grandes mudanças políticas e econômicas, de uma maneira predominantemente não-violenta no nível político. O século XIX foi caracterizado por conflitos agressivos entre o partido conservador, que representava os oligarcas latifundiários aliados da igreja católica, e o partido liberal, que representava as elites litorâneas interessadas no comércio e na secularização (Collins, 2018, p. 301). Em 1925, os militares tomaram o poder dos liberais, mas se identificaram com a reforma, não se tornando uma força opressora. Assim, o governo militar de 1972-1976 implementou uma revolução nacionalista visando a modernização e retirou-se do poder pacificamente em uma transição negociada em 1979. O fato de não haver violência sistêmica permitiu que os principais atores da sociedade civil tivessem mais liberdade para se organizar e influenciar a agenda política, como ilustram as conquistas bem sucedidas do movimento de mulheres. O Equador foi o primeiro país latino-americano a conceder o direito de voto às mulheres em 1929 e, desde então, o campo 
da defesa de direitos políticos resultou em novas conquistas como a adoção de cotas de gênero para eleições legislativas em 1998 (Piatti-Crocker, 2019). O país permite a exploração das dinâmicas da agenda em um país onde as lutas por direitos de cidadania e inclusão política de povos indígenas e afro-equatorianos produziram um sucesso importante em um contexto onde o racismo tem raízes profundas (Collins, 2018).

Como ocorrido no Brasil, a chegada de Correa ao poder em 2006 levou à implementação de uma agenda reformista alinhada com o "novo socialismo do século 21", revertendo as políticas neoliberais anteriores. Correa chegou à presidência em um contexto em que os equatorianos estavam fartos de políticos, com cidadãos com baixa confiança nas instituições políticas, alta volatilidade eleitoral e um contexto econômico precário. Correa venceu as eleições presidenciais com um forte discurso contra a partidocracia, alimentando os sentimentos antipartidários do povo, o que o levou a ser considerado um presidente populista (García-Bryce, 2019). A agenda de Correa foi caracterizada pela chamada "Revolução Cidadã", um projeto político materializado na reforma constitucional de 2008, que tinha por conceito central o buen vivir ("viver bem"), enfatizando a importância de "viver em harmonia e equilíbrio com a natureza e outros seres humanos, rejeitando o consumismo e o individualismo em favor da sustentabilidade e da comunidade" (Collins, 2018, p. 307). Em 2008, o Equador foi o primeiro Estado a consagrar os direitos da natureza em sua Constituição (Eisenstadt \& West, 2019). Mesmo que Correa tenha promovido uma agenda política que foi no início altamente influenciada por movimentos sociais e comunidades indígenas particulares, o presidente entrou em choque com tais movimentos e se distanciou de grupos de esquerda, promovendo, por exemplo, a mineração em larga escala - uma prática criticada fortemente pelas associações ambientais. Importante em termos de pesquisa de formação de agenda é que Correa assinou uma das leis de mídia mais restritivas da América Latina. Apesar disso, durante sua presidência a qualidade da democracia melhorou significativamente, os níveis de pobreza foram reduzidos e a confiança dos cidadãos nas instituições atingiu níveis sem precedentes. Lenín Moreno, o atual presidente do Equador, que foi vice-presidente de Correa de 2007 a 2013, derrotou Guillermo Lasso, o candidato da oposição, em 2017. Moreno parece ter reconhecido as contradições da presidência de Correa e vem trabalhando para tomar decisões a favor de direitos indígenas e meio ambiente (Eisenstadt \& West, 2019).

Finalmente, vale mencionar que a região da América Latina e Caribe é a segunda região mais propensa a desastres no mundo, com 152 milhões de pessoas afetadas por 1.205 desastres no período 2000-2019. A análise de como os países da região reagem a essas catástrofes é interessante, visto que seus efeitos na formação das agendas estão bem documentados entre os estudiosos do tema (Jones \& Baumgartner, 2005; Kingdon, 1984). Em 2016, por exemplo, o Equador sofreu um dos terremotos mais graves de sua história recente, que levou à declaração de estado de emergência. E outros exemplos podem ser encontrados na região, entre os mais recentes e importantes estão os incêndios florestais de 2019 na região amazônica, que resultaram em intensos debates políticos nas regiões afetadas - Brasil e outros países - e na mobilização e protesto em todo o mundo como parte da crescente consciência ambiental que emerge globalmente. 


\section{CONCLUSÃO}

Os dados do Comparative Agendas Project (CAP) permitem um nível inédito de comparação entre políticas e elaboração de políticas públicas tanto dentro de um mesmo projeto como externamente entre diferentes países. Embora alguns dos dados discutidos neste artigo ainda estejam em desenvolvimento, o objetivo - assim como ocorre com todos os dados do CAP - é que estejam à disposição de forma aberta e gratuita a pesquisadores, estudantes, profissionais e outros interessados. Tão importante quanto esses dados recém-introduzidos são os existentes e em constante crescimento fora da América Latina, que constituem um banco de dados de atenção política verdadeiramente global. Este trabalho só é possível devido à dedicação dos membros das equipes e investigadores principais, além da boa vontade da comunidade em geral e da possibilidade de contar com um Master Codebook. Embora muitos pesquisadores possam não se dar conta dos detalhes envolvidos na criação desse livro de códigos, a transparência sobre o processo de sua criação, funcionamento e também limitações, pode ajudar a ampliar a confiança nos dados que proporciona.

Os dados permitem que pesquisadores, formuladores de políticas e estudantes avaliem as tendências nas atividades envolvidas na elaboração de políticas públicas ao longo do tempo e entre as nações, reduzindo custos relacionados a obtenção de dados capazes de subsidiar a pesquisa comparativa. A ampliação da comunidade do CAP para a América Latina permitirá ricas análises entre países, explorando questões de interesse para os estudos sobre a região. No entanto, o potencial dessa expansão do projeto vai além de abranger um novo território. Ter grandes conjuntos de dados comparáveis permitirá a investigação de semelhanças e diferenças nas dinâmicas da agenda na América Latina e em outras regiões do mundo, abordando questões como o impacto de diferentes projetos institucionais nos resultados das políticas públicas, e como as diferentes configurações do Estado e das relação entre os cidadãos pode afetar as prioridades. Por exemplo, os países latino-americanos também têm questões centrais (economia, defesa, relações internacionais e operações governamentais) que tendem a dominar as agendas (Jennings et al., 2011), ou essas são inundadas por outras preocupações fundamentais, como a violência política? Como os laços culturais e econômicos especiais entre a América Latina e a Espanha (Chaqués-Bonafont, Palau, \& Baumgartner, 2015) se manifestam em termos de convergência de agendas? Tão importantes quanto as características regionais são os desafios que as ameaças globais (como as mudanças climáticas) ou fenômenos políticos (como o populismo), representam para as democracias liberais. Essas são questões em que se torna essencial contar com uma visão de mundo para além daquela ocidental e do Norte global.

Nos últimos anos, o crescimento do populismo na América Latina, mas também nos Estados Unidos e na Europa, exemplifica a crise da representação política e, em particular, a incapacidade das instituições tradicionais e dos líderes políticos de integrar e representar a vontade dos cidadãos (Kats \& Mair, 1995; Laclau, 2005). A globalização do mercado e o triunfo do liberalismo induziram a convergência política, desarraigando os partidos de sua base social, promovendo o desenvolvimento de castas políticas contra as quais os partidos populistas revelaram ressentimentos agora politizados, relacionados às desigualdades econômicas (à esquerda) e à diluição das identidades étnicas e nacionalistas (à direita) (Roberts, 2019). Os partidos populistas têm conseguido mobilizar cidadãos que ocupam uma posição marginal na economia globalizada ou que sentem sua comunidade nacional ameaçada por sociedades multiculturais. Isso ocorreu na Europa Ocidental, onde os sistemas partidários foram historicamente fundamentados em divisões de classe, mas também nos 
RAP | 0 Comparative Agendas Project na América Latina: dados e codificação

Estados Unidos e na América Latina com os partidos mais fracos como agentes de mobilização. O crescimento do populismo de esquerda na América Latina, por exemplo na Venezuela, Equador ou Bolívia, e também em países do sul da Europa, especialmente no rescaldo da crise financeira iniciada em 2008, promete aos eleitores proteção social contra o liberalismo de mercado e remédios para as consequências de políticas de ajuste estrutural (Della Porta, Fernández, Kouki, \& Mosca, 2017; Kriesi \& Pappas, 2015). O populismo de direita, como o de Marie Le Pen na França, Donald Trump nos Estados Unidos ou Bolsonaro no Brasil, cresceu paralelamente politizando os aspectos culturais mais do que os socioeconômicos. Eles são orientados a proteger suas comunidades nacionais dos imigrantes e da globalização econômica, que são percebidos como uma ameaça (Wodak, KhosraviNik, \& Mral, 2013). A ampliação do projeto CAP permitirá pesquisar até que ponto a agenda dos líderes populistas converge internacionalmente, o que é uma questão de grande interesse na pesquisa comparativa. 


\section{REFERÊNCIAS}

Adler, E. Scott., \& Wilkerson, John. D. (2013). Congress and the politics of problem solving. Cambridge, UK: Cambridge University Press.

Annesley, C., Engeli, I., \& Gains, F. (2015). The profile of gender equality issue attention in Western Europe. European Journal of Political Research, 54(3), 525-542.

Baumgartner, F. R., Brouard, S., Green-Pedersen, S., Jones, B. D., \& Walgrave, S. (2011). The Dynamics of Policy Change in Comparative Perspective. Comparative Political Studies, 44(8), 947-972.

Bevan, S., Baumgartner, F., Johnson, E., \& McCarthy, J. (2013). Understanding Selection Bias, Time-Lags and Measurement Bias in Secondary Data Sources: Putting the Encyclopedia of Associations Database in Broader Context. Social Science Research, 42(6), 1750-1764.

Bevan, S., \& Jennings, W. (2014). Representation, Agendas and Institutions. European Journal of Political Research, 53(1), 37-56.

Boydstun, A. E. (2013). Making the News: Politics, the Media, and Agenda Setting. Chicago, IL: University of Chicago Press.

Bruneau, T. C., \& Goetze, R. B., Jr. (2019). From Tragedy to Success in Colombia: The Centrality of Effectiveness in Civil-Military Relations. Washington, DC: William J. Perry Center for Hemispheric Defense Studies. Recuperado de http://hdl.handle. net/10945/62500

Chaqués-Bonafont, L., Palau, A. M., \& Baumgartner, F. R. (2015). Agenda dynamics in Spain. New York, NY: Springer.

Collins, J. N. (2018). Ecuador: change and Continuity after ten years of nw left revolution. In H. F. Kline, C. J. Wade, \& H. J. Wiarda. (Eds.), Latin American Politics and Development. London, UK: Routledge.

Crandall, B. H. (2018). Brazil: The Politics of Elite Rule. In H. F. Kline, C. J. Wade, \& H. J. Wiarda. (Eds.), Latin American Politics and Development. London, UK: Routledge.

Della Porta, D., Fernández, J., Kouki, H., \& Mosca, L. (2017). Movement parties against austerity. London, UK: John Wiley \& Sons.
Dowding, K., Hindmoor, A., \& Martin, A. (2016). The Comparative Policy Agendas Project: Theory, Measurement and Findings. Journal of Public Policy, 36(1), 3-25.

Eisenstadt, T. A., \& West, K. J. (2019). Who Speaks for Nature? Indigenous Movements, Public Opinion, and the Petro-state in Ecuador. Oxford, UK: Oxford University Press.

Fogel, B. (2019). Brazil: Corruption as a Mode of Rule: Tracing the roots of corruption in Brazil from Vargas to Bolsonaro reveals a political strategy that has long been woven into the fabric of Brazilian politics. NACLA Report on the Americas, 51(2), 153-158.

García-Bryce, I. (2019). Populism across the Andes during the 20th and Early 21st Centuries. Oxford: UK: Oxford Research Encyclopedia of Latin American History.

Gonçalves, F., \& Niedhardt, A. C. (2019). Agenda governamental brasileira: uma análise da capacidade e diversidade nas prioridades em políticas públicas no período de 2003 a 2014, Cadernos Gestão Pública e Cidadania, 24(78), 1-22.

Green-Pedersen, C., \& Wilkerson, J. (2006). How agenda-setting attributes shape politics: basic dilemmas, problem attention and health politics developments in Denmark and the US. Journal of European Public Policy, 13(7), 1039-1052.

Guiraudon, V. (2000). European Integration and Migration Policy: Vertical Policy Making as Venue Shopping. Journal of Common Market Studies, 38(2), 251-271.

Jennings, W., Bevan, S., Timmermans, A., Breeman, G., Brouard, S., Chaques, L. ... Mortensen, P. B. (2011). Effects of the Core Functions of Government on the Diversity of Executive Agendas. Comparative Political Studies, 44(8), 1001-1030.

Jones, B. D., \& Baumgartner, F. R. (2005). The politics of attention: How government prioritizes problems. Chicago, IL: University of Chicago Press.

Jones, B. D., Baumgartner, F. R., Breunig, C., Wlezien, C., Soroka, S., Foucault, M. ... Walgrave, S. (2009). A general empirical law of public budgets: A comparative analysis. American Journal of Political Science, 53(4), 855-873. 
Katz, R. S., \& Mair, P. (1995). Changing models of party organization and party democracy: the emergence of the cartel party. Party politics, 1(1), 5-28.

Kline, H. F. (2018). Colombia: Is Guerrila violence near its end? In H. F. Kline, C. J. Wade, \& H. J. Wiarda. (Eds.), Latin American Politics and Development. London, UK: Routledge.

Kline, H. F., Wade, C. J., Wiarda, H. J. (2018). Latin American Politics and Development. London, UK: Routledge.

Kriesi, H., \& Pappas, T. S. (Eds.). (2015). European populism in the shadow of the great recession (pp. 1-22). Colchester, UK: Ecpr Press.

Laclau, E. (2005). On populist reason. New York, NY: Verso.
North, L. L., \& Clark, T. D. (2018). Dominant Elites in Latin America: From Neo-Liberalism to the 'Pink Tide. Cham, Switzerland: Palgrave Macmillan.

Piatti-Crocker, A. (2019). The Diffusion of Gender Policy in Latin America: From Quotas to Parity. Journal of International Women's Studies, 20(6), 44-59.

Roberts, K. M. (2019). Crises of Representation and Populist Challenges to Liberal Democracy. Chinese Political Science Review, 4(2), 188-199.

Spencer, D. E. (2019). Security Challenges of the New Colombian Administration. PRISM, 8(1), 82-95.

Wodak, R., KhosraviNik, M., \& Mral, B. (Eds.). (2013). Right-wing populism in Europe: Politics and discourse. London, UK: A\&C Black.

\section{Shaun Bevan}

https://orcid.org/0000-0001-7717-7822

Ph.D. em Ciência Política; Conferencista sênior no Departamento de Política e Relações Internacionais da Universidade de Edimburgo. E-mail: shaun.bevan@gmail.com

\section{Anna M. Palau}

https://orcid.org/0000-0002-3473-1114

Ph.D. em Ciência Política; Professora Associada Serra Húnter do Departamento de Ciência Política, Direito Constitucional e Filosofia do Direito da Universidade de Barcelona. E-mail: apalau@ub.edu 